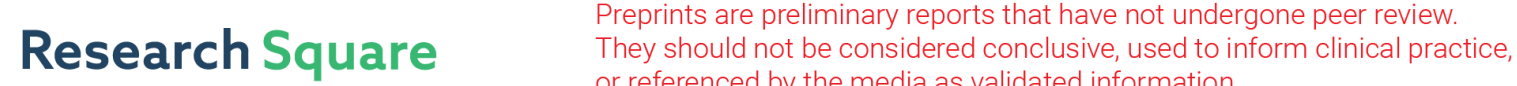 or referenced by the media as validated information. \\ Towards Sustainable and Environmentally Friendly Metallic Powder Production
}

MELCHOR SALAZAR MARTINEZ ( $\square$ msalazarm@ipn.mx)

INSTITUTO POLITECNICO NACIONAL

Flavio Américo Lagos-Galván

Instituto Mexicano del Petróleo: Instituto Mexicano del Petroleo

\section{Research Article}

Keywords: Iron aluminide, FeAl, intermetallic, powders, environmentally friendly

Posted Date: June 17th, 2021

DOI: https://doi.org/10.21203/rs.3.rs-620114/v1

License: (9) This work is licensed under a Creative Commons Attribution 4.0 International License.

Read Full License 


\title{
Towards sustainable and environmentally friendly metallic powder production
}

\author{
Melchor Salazar Martínez ${ }^{1 *}$, Flavio Américo Lagos-Galván² \\ ${ }^{1}$ Centro de Innovación e Integración de Tecnologías Avanzadas, Unidad Papantla Veracruz del Instituto \\ Politécnico Nacional, Innovation Coordination, Papantla de Olarte, Ver., C.P. 93400, México. \\ ${ }^{2}$ Instituto Mexicano del Petróleo, Product Technology Direction, Eje Central Lázaro Cárdenas 152, C.P. \\ 07730, CDMX, México. \\ *Corresponding author: msalazarm@ipn.mx
}

\begin{abstract}
Intermetallic $\mathrm{Fe}-\mathrm{Al}$ compounds have become very interesting materials due to their properties, such as good corrosion resistance, high-temperature resistance, high resistance/weight ratios, creep resistance, good wear resistance, and low cost, including some applications where they could replace stainless steels. However, their low ductility at room temperature has limited their use. One of the solutions is to generate powders of these intermetallics and press them in the wished form. Current production methods of this type of powders are very high energy-consuming, polluting, and harmful for handling for human beings. Because of the environmental situation in our planet, it is necessary to develop more environmentally friendly processes, which have lower energy requirements. Therefore, a comparison of a novel water vapor-based $\mathrm{FeAl}$ powder manufacture process with Mechanical Alloying (MA), one of the most commonly used processes to produce this type of powder is made in this work. This comparison aims to focus on the advantages of the novel process concerning MA, the last one, considering environmental as well as energy criteria.
\end{abstract}

Keywords: Iron aluminide, FeAl, intermetallic, powders, environmentally friendly.

\section{List of abbreviations}

$\mathrm{E}_{\text {ball }}=$ Required energy for producing $\mathrm{FeAl}$ in a Ball mill

$\mathrm{E}_{\text {mill }}=$ Required energy for milling

$E_{h t}=$ Required energy for heat treatment

$D_{\mathrm{f}}=$ Feed particle diameter

$\mathrm{d}=$ Final product particle diameter

$\mathrm{E}_{\mathrm{b} 1}=$ Required energy for the first milling step in Ball mill

$W_{h}=$ Specific grinding energy for a Ball mill

$\mathrm{T}=$ Required mill capacity in short Ton/hr

$\mathrm{E}_{\text {Ball total }}=$ total theoretical required energy for a Ball mill

$\mathrm{E}_{\text {Ball real }}=$ real energy to be supplied for process in Ball mill

$\mathrm{E}_{\mathrm{NP}}=$ Energy required for the new process

$\mathrm{Cp}=$ Heat capacity

$\mathrm{E}_{\mathrm{rib}}=$ Energy required for ribbons production

$\mathrm{E}_{\mathrm{dis}}=$ Energy required for ribbons disintegration 


\section{Introduction}

Iron aluminide intermetallics were developed as structural and coating material due to their excellent hightemperature oxidation and corrosion resistance in aggressive environments, low density, high strength-/weight ratios, and low cost (conservation of strategic elements, such as aluminum and iron (Zamanzade et al. 2016; Morris et al. 2011; Paidar 2015). Due to such properties, these intermetallic compounds have a great potential for substituting stainless steel in some industrial applications at elevated temperatures (Zamanzade et al. 2016; Morris et al. 2011) and also have advantages over nickel and titanium aluminides) (Feijó et al. 2014). However, they have industrially limited use because of their low ductility at room temperature (Chen et al. 2001; Salazar et al. 2016).

Attempts have been made to improve the low ductility at room temperature by appropriate processing and by the addition of alloying elements, through melting and conventional casting and powder metallurgy (PM) methods (Feijó et al. 2014; Sleboda et al. 2007; Alexander et al. 1998; Godlewska et al. 2003; Hu et al. 2003; Pithawalla et al. 2002; Meyer et al. 1999), however, the latter have shown higher tensile elongations and fracture energy on impact testing, since much finer microstructures can be produced (Feijó et al. 2014; Sleboda et al. 2007; Alexander et al. 1998). Some of the fabrication processes of FeAl are mechanical alloying (MA), chemical synthesis, laser-based processes, combustion reaction, and flow-levitation methods. MA is the most common process used for producing $\mathrm{FeAl}$ intermetallic compounds.

The industry has always been looking for ways to reduce the energy consumed in manufacturing processes, for economic reasons, but at present, due to the environmental conditions in which our planet encounters, it is important to develop more environmentally friendly and sustainable manufacturing processes (Dornfeld 2014; Paul et al. 2014; Campatelli et al. 2015). One of these ways is to reduce the machining to obtain the final product (Campatelli et al. 2015). This can be achieved by PM techniques, hence the relevance of powder production. In this work, a novel, non-polluting, and economical method are developed by the authors for producing $\mathrm{FeAl}$ powders (Salazar et al. 2016). The method can be used for any aluminide with high aluminum content). This process uses mainly rapid solidification and steam.

Calculations are performed to estimate the energy required to produce $\mathrm{FeAl}$ powders by MA and the new process and are compared to demonstrate energy savings as well as other benefits.

\section{Fabrication of FeAl Powders}

\subsection{Using novel process}

The novel fabrication process consists essentially of two simple main steps (Salazar et al. 2016):

a) $\mathrm{FeAl}$ ribbons production by rapid solidification (melt spinning) from solid aluminum and iron pieces, not from elemental powders as used by MA.

b) $\mathrm{FeAl}$ ribbons produced are exposed to steam in a container for their disintegration and transformation into powder. The particle size and its distribution can be controlled by the addition of alloying elements.

\subsection{Using MA process}

MA is a solid-state powder processing technique that involves the repeated welding, fracturing, and re-welding of a mixture of powder particles, commonly in a high-energy ball mill producing alloys and microstructures that are not possible to produce by standard metallurgical practices such as casting and forging. MA uses aluminum and iron powders as raw materials. This process is carried out in different types of equipment, such as vibratory and planetary mills, high-speed blenders and shakers (e.g. high-energy Spex), and large-diameter ball mills (Mhadhbi et al. 2013).

Figure 1 shows the complete fabrication process of FeAl powders by both processes. 


\section{Required Energy Comparison for Producing FeAl Powders by MA and New Process}

In this section, a comparison between the required energy for MA and the novel process for producing FeAl powder was performed, which is schematically represented in figure 2 . This figure shows a representation of the steps for each involved process for computing the energy involved for each case. First, the required energy for a conventional MA process using a ball mill was computed. The second part corresponds to the estimation of the required energy for our new process, with both steps (Rapid solidification and disintegration), already described in 2.1 .

For the calculation of the energy required in the MA process it is important to take into account that the powders obtained have a partially ordered structure and therefore, a later heat treatment is necessary to get a fully ordered structure (Hu et al. 2003; Tecnum, University of Navarra, Spain), as shown in figure 2.

\subsection{Required energy for MA}

In this section, the use of a ball mill is considered because it is the most common process used.

The theoretical energy $\left(E_{\text {Ball }}\right)$ required for producing FeAl powder was estimated considering the energies required in the two process steps: 1$)$ The milling itself $\left(E_{\text {mill }}\right)$ with two stages, and 2$)$ the heat treatment $\left(E_{h t}\right)$ applied later to the produced powder. Required energy can be expressed in the following way:

$$
E_{\text {ball }}=E_{\text {mill }}+E_{h t}
$$

For the calculation of required energy the following considerations are made: the intermetallic compound has a high hardness, the mean size for the feed particle diameter $D_{f}=10 \mathrm{~mm}$, final product particle diameter $d=40$ $\mu \mathrm{m}$ (mean size of the powder particles produced). The milling energy was computed according to Tsakalakis and Stamboltzis (Tsakalakis et al. 2004). The milling process is considered to be undertaken in two stages:

$$
E_{\text {mill }}=E_{b l}+E_{b 2}
$$

For the first milling stage, the specific grinding energy $W_{h}$ is computed according to the material hardness. In this case, since iron aluminide is considered a hard compound, $W_{h}$ can be expressed as:

$$
W_{h}=1,961\left(D_{f}^{0.193}\right) x d^{-0.962}
$$

substituting the values of $D_{f}$ and $d$ we have

$$
W_{h}=67.6544 \frac{\mathrm{kW}}{\mathrm{sh}} \mathrm{Ton}
$$

The power draw $P$ for the ball mill is given by

$$
P=0.1169 W_{h} D_{f}^{0.193} d^{-0.962} T
$$

where $T$ is the required mill production capacity in short Ton/hr (in this case, 1), resulting

$$
P=272.853 \mathrm{kWh} / \mathrm{Ton}
$$

This result is correlated with the common value given for the computation of required energy for ball mills, according to the Denver rule, resulting $E=340 \mathrm{kWh} / \mathrm{on}$ and this gives for the first milling step:

$$
E_{b l}=1.224 \times 10^{6} \mathrm{~kJ} / \mathrm{Ton}
$$

The second milling stage requires about 33\% more energy than this one (Mhadhbi et al. 2013), resulting:

$$
E_{b 2}=1.628 \times 10^{6} \mathrm{~kJ} / \mathrm{Ton}
$$


and the total milling energy (from Eq. 2) results:

$$
E_{\text {mill }}=2.852 \times 10^{6} \mathrm{~kJ} / \mathrm{Ton}
$$

As mentioned above, a heat treatment is required for powders produced by MA. Considering that the heat treatment for this intermetallic compound is carried out at $650{ }^{\circ} \mathrm{C}$ (Mhadhbi et al.2013), the energy involved for the process to reach that temperature $\left(E_{h t}\right)$ can be computed with the $C p=0.51 \mathrm{~kJ} / \mathrm{kg}{ }^{\circ} \mathrm{K}$ according to (Piatkowski et al. 2013) as follows:

$$
\begin{gathered}
E_{h t}=C p \Delta T m \\
E_{h t}=0.457 \times 10^{6} \mathrm{~kJ} / \mathrm{Ton}
\end{gathered}
$$

where $m$ is the mass considered, for this case, 1 ton.

With this result, the minimum theoretical energy required for the full process according to equation (1) is:

$$
E_{\text {ball }}=3.309 \times 10^{6} \mathrm{~kJ} / \mathrm{Ton}
$$

Considering the energy consumed by the particle surface relative to the original particle surface energy, the efficiency for this type of process, is very low, $5 \%$ (Mhadhbi et al. 2013). This delivers the total theoretical required energy:

$$
E_{\text {Ball total }}=\frac{\left(3.309 \times 10^{6}\right)}{0.05 \mathrm{~kJ} / \text { Ton }}=6.618 \times 10^{7} \mathrm{~kJ} / \text { Ton }
$$

Most energy losses for this process are mainly in the form of noise and heat. For hard powders, milling efficiency is very low, about $3 \%$ because their particles adhere to each other and the ball impacts become inelastic. This efficiency gives the real energy to be supplied:

$$
E_{\text {Ball real }}=\frac{6.618}{0.03 \times 10^{7} \mathrm{~kJ} / \text { Ton }}=2.206 \times 10^{9} \mathrm{~kJ} / \text { Ton }
$$

\subsection{Required energy for the new process}

As mentioned above, the new process consists of two main stages, the ribbons production by rapid solidification and their subsequent disintegration with steam. Therefore, the energy required for this new process $\left(E_{N P}\right)$ can be expresses for the following equation:

$$
E_{N P}=E_{r i b}+E_{d i s}
$$

$E_{N P}$ - Energy required for the new process

$E_{r i b}$ - Energy required for ribbons production

$E_{d i s}-$ Energy required for ribbons disintegration

For the first step, the production of ribbons, the required energy $\left(E_{r i b}\right)$ will take as reference value the industrial process CASTRIP (Campbell 2004; Ibarrondo 2008) for melt spinning energy. This was made because of the scarcity of data for scaling-up our process from laboratory scale to industrial practice. The reported value is $0.18 \mathrm{GJ} / \mathrm{Ton}=1.8 \times 10^{5} \mathrm{~kJ} /$ Ton. It is important to take into account that this value is given for steel casting process in thin slabs and in our case the required energy is lower, according to composition, with 60 at.\% aluminium. 
The energy for the second step (disintegration using steam, $E_{d i s}$ ) is given by the energy for heating water to the boiling point $\left(E_{d i s} I\right)$ and the corresponding latent heat for vapor production $\left(E_{d i s}\right)$ :

$$
E_{d i s}=E_{d i s 1}+E_{d i s 2}
$$

Where

$$
\begin{gathered}
E_{\text {dis } 1}=C p \Delta T m=\left(4.1813 \mathrm{~kJ} / \mathrm{kg}^{\circ} \mathrm{K}\right)\left(100-25^{\circ} \mathrm{K}\right) \times 10^{3} \mathrm{~kg} / \text { Ton }=3.13 \times 10^{5} \mathrm{~kJ} / \mathrm{Ton} \\
E_{\text {dis } 2}=m Q_{\text {lat }}=2.257 \times 10^{3} \mathrm{~kJ} / \mathrm{kg}\left(10^{3} \mathrm{~kJ} / \mathrm{Ton}\right)=2.257 \times 10^{6} \mathrm{~kJ} / \text { Ton }
\end{gathered}
$$

The total energy required for the disintegration step results:

$$
E_{\text {dis }}=(0.313+2.257) \times\left(10^{6} \mathrm{~kJ} / \mathrm{Ton}\right)=2.570 \times 10^{6} \mathrm{~kJ} / \mathrm{Ton}
$$

Total energy required for the process according to the equation 6 is:

$$
E_{N P}=(0.18+2.570) \times 10^{6} \mathrm{~kJ} / \text { Ton }=2.75 \times 10^{6} \mathrm{~kJ} / \mathrm{Ton}
$$

According to this result, it is important to note that the energy required for water vapor generation is considerable. This opens a possible optimization option for the use of steam in this process, if further savings are strived.

An average value for this type of milling process obtained from the literature is in the range $2.0 \times 10^{12}$ to $9.757 \times 10^{12} \mathrm{~kJ} /$ Ton, according to industrial data (EPRI Center of Materials Production, 2000).

The obtained value by us for ball mill MA process, $\left(W_{\text {Ball real }}\right)=2.206 \times 10^{9} \mathrm{~kJ} /$ Ton, is lower than those reported for the industrial practice, as can be seen above. The employed model considers particle sizes and hardness referred to a large number of analyzed systems for the ball mill.

The proposed new process offers important energy savings, considering that a more efficient process (rapid solidification) and then, water vapor are employed. The results obtained here show an important difference between the theoretical energies used for the ball mill and that used for the new process (at least 3 orders of magnitude).

\section{Other benefits from the new process}

Most of the processes used to produce iron aluminide powders use elemental powders of iron and aluminum as raw materials. Therefore, some other advantages of the new process refer to the absence of particle emissions to the environment and the corresponding health and security hazards originated by suspended particles with high pyrogenic character caused by excessive impact energy transfer. This condition involves important security measures to be adopted, including handling the material under inert gas atmosphere, such as argon. The new process prevents health risks resulting from powders or hazardous conditions, which can result from the contact of the mentioned produced powders with the skin or when inhaled. No lubricants or binders, such as stearates, as is the case in MA (Soni 2001; Khaerudini 2013), are used. The corresponding pollution and environmental hazards by these agents are also reduced.

Moreover, the metal powders produced by grinding are hardened, irregular in shape and have low fluidity and filling density. 
In the case of the novel process, there is no contamination with the material from the milling vessel nor from ball debris.

Fixed or investment costs (CAPEX) considered for ball mill are also saved through this process, as well as the corresponding operating costs (OPEX) for the milling process. Environmental and health risks are remarkably reduced too. The ease to handle the material as ribbons or powder without any further security measure, such as inert gas atmosphere or special protection equipment for the personnel, represents also important savings in operation costs.

The reaction between water vapor and aluminum also generates hydrogen (Salazar et al. 2016; Salazar, Pérez $\&$ Rosas, 2005). Other authors have proposed hydrogen production using iron aluminides (López-Miranda et al. 2019; Romero-Romero et al. 2014; García de León et al. 2013). This suggests that this method could be used to produce hydrogen, which requires more studies.

These advantages are very important in this industrial branch, which is very intensive energy demanding one.

\section{Conclusions}

Required energy for intermetallic FeAl manufacturing by the new proposed process is considerable lower (at least 3 orders of magnitude) than that required by MA, the commonly used process. Besides energy savings, environmental, health and work risks are remarkably reduced too, since particle energy is noticeably reduced. This process results very economical for iron aluminide powder fabrication with high aluminum content, and other aluminides such as titanium and nickel aluminides among others.

\section{Declarations}

Not applicable.

\section{References}

Alexander, D.J., Maziasz, P. J. \& Wright, J. L. (1998) Processing and alloying effects on tensile and impact properties of FeAl alloys. Mat. Sci. Eng. A, A258, p. 276-284. http://doi.org/10.1016/S0921-5093 (98)00945-9.

Campatelli, G., Scippa, A., Lorenzini, L. \& Sato, R. (2015) Optimal Workpiece Orientation to Reduce the Energy Consumption of a Milling Process. Int. J. of Precision Engineering and Manufacturing-Green Technology, 2(1), p. 5-13. https://doi.org/10.1007/s40684-015-0001-3.

Campbell, P. C. (2004) The CASTRIP Process: A revolutionary casting technology, an exciting opportunity for unique steel products or a new model for steel Micro-Mill?.

Chen G. L. \& Liu C. T. (2001) Moisture induced environmental embrittlement of intermetallics Inter. Mater. Rev., 46, p. 253-270. https://doi.org/10.1179/095066001771048718.

Dornfeld, D.A. (2014) Moving towards green and sustainable manufacturing, Int. J. of Precision Engineering and Manufacturing-Green Technology, 1(1), p.63-66. https://doi.org/10.1007/s40684-014-0010-7.

EPRI Center of Materials Production, Metal powder production, Industry Segment Profile, SIC 33991, Columbus, OH, U.S.A, 2000.

Feijó Leão Borges, D. Crocce Romano Espinosa \& D. Geraldo Schön C. (2014) Making iron aluminides out of scrap. J. Mater. Res. Technol, 3 (2), p.101-106. https://doi.org/10.1016/j.jmrt.2013.12.002.

García de León Monter, E., Tellez,O., Patiño-Carachure, C., Angeles Chávez, (C) \& Rosas, R. (2013) Evaluation of hydrogen embrittlement in FeAl assisted by mechanical milling. Acta Microscopica 22(3), p.262-268. https://acta-microscopica.org/acta/article/view/242.

Godlewska E., Szczepanik, S., Mania, R., Krawiarz, J. \& Koziñski, S. (2003) FeAl materials from intermetallic powders. Intermeallics, 11, p. 307-312. https://doi.org/10.1016/S0966-9795(02)00247-9. 
Hu, W., Kato, T. \& Fukumoto, M. (2003) Synthesis and Characterization of Nanocrystalline Iron Aluminide Intermetallic Compounds. Mat. Trans., 44(12), p. 2678-2687. https://doi.org/10.2320/matertrans.44.2678.

Ibarrondo I. (2008) Review of the Strip Casting Technology by Twin Roll Method, San Sebastian, Spain. ISBN 978-84-612-9489-3.

Khaerudini, D.S., Sardjono, M. P., Tetuko, A. P., Sebayang, P. \& Ginting, M. (2013) Effect of $\mathrm{CeO}_{2}$ addition on the properties of FeAl based alloy produced by mechanical alloying technique, AIP Conf. Proc. 1555, 7, p. 7-10. https://doi.org/10.1063/1.4820980.

López-Miranda, J. L. \& Rosas, R. (2019) Hydrogen generation by aluminum hydrolysis using the Fe2Al5 intermetallic compound, International Journal of Hydrogen Energy 41(6), p. 4054-4059. https://doi.org/10.1016/j.ijhydene.2016.01.012.

Meyer, M., Mendoza-Zélis, L. \& Sánchez, F. H. (1999) Mechanical milling of the intermetallic compound AlFe. Physical Review B, 60 (5), p. 3206-3212. https://doi.org/10.1103/PhysRevB.60.3206.

Mhadhbi, M., Suñol, J. J.\& Khitouni, M. (2013) Influence of Heat Treatments on the Structure of FeAl Powders Mixture Obtained by Mechanical Alloying. Physics Procedia, 40, p. 38-44. https://doi.org/10.1016/j.phpro.2012.12.005.

Morris D.G. \& Muñoz-Morris, M. A. (2011) Recent Developments Toward the Application of Iron Aluminides in Fossil Fuel Technologies. Adv, Eng. Mater., 13, p. 43-47. https://DOI: 10.1002/adem.201000210.

Paidar V. (2015) Iron Aluminides and Petr Kratochvíl. Acta Physica Polonica A, 128, p. 467-469. https://DOI: 10.12693/APhysPolA.128.467.

Paul, I. D., Bhole, G. P. \& Chaudhari, J. R. (2014) A Review on Green Manufacturing: It's Important, Methodology and its Application. Procedia Materials Science, 6, p. 1644-1649. https://doi.org/10.1016/j.mspro.2014.07.149.

Piatkowski, J., Przeliorz, R. \& Jablonska, M. (2013) The Specific Heat Capacity and Oxidation Kinetics of $\mathrm{NiAl}, \quad \mathrm{FeAl}$ and TiAl Alloys. Solid State Phenomena, 203-204, p. 431-434. https://doi.org/10.4028/www.scientific.net/SSP.203-204.431.

Pithawalla, Y.B., Deevi, S. C. \& El-Shall M. S. (2002) Preparation of ultrafine and nanocrystalline FeAl powders. Mat. Sci. Eng. A-Struct, A329-331, p. 92-98. https://doi.org/10.1016/S0921-5093(01)015593.

Romero-Romero, J. R., López-Miranda, J. L., Esparza, R., Espinosa-Medina, M. A. \& Rosas, R. (2014) Phase Evaluation and its Hydrogen Correlation of the FeAl3 and FeAl2 Intermetallic Alloys during Mechanical Ball-Milling with wáter, Materials Science Forum, 793, p. 143-149. https://doi.org/10.4028/www.scientific.net/MSF.793.143.

Salazar, M., López, V. H., Bautista, N., Cuamatzi, R. \& Lagos, F. A. (2016) FeAl powder fabrication by rapid solidification and water vapour-based process. Powder Metallurgy, 59 (5), p. 314-320. https://doi.org/10.1080/00325899.2016.1228572.

Salazar, M., Pérez, R. \& Rosas, G. (2005) Environmental embrittlement characteristics of the AlFe and AlCuFe intermetallic systems. J. New Mater. Electrochem. Syst 8(2), p.97-100.

Sleboda T. \& Doniec K. (2007) The effect of alloy powder morphology on microstructural evolution of hot worked P/M FeAl. Archives of Materials Science and Engineering, 28 (10), p. 613-616.

Soni, P.R. (2001) Mechanical Alloying: Fundamentals and Applications, 1st Edition, Cambridge International Science Publishing, Cambridge, p. 6-30.

Tecnun, University of Navarra, Spain. www.tecnun.unav.edu.

Tsakalakis, K. G., \& Stamboltzis, G. A. (2004) Modeling the specific grinding energy and ball-mill scale-up IFAC 2004, Nancy, France. Conference: Presented at the 11th Symposium on Automation in MMM IFAC.

Zamanzade M., Barnoush A. \& Motz, C. A. (2016) Review on the Properties of Iron Aluminide Intermetallics. Crystals, 6, 10, p. 1-29. https://doi.org/10.3390/cryst6010010. 


\section{Figures}

Fig. 1 New fabrication process of FeAl powders (Salazar, 2016).

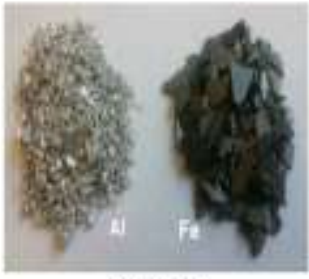

Rawmaterial

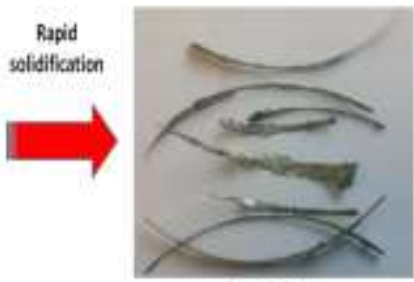

fealritboes
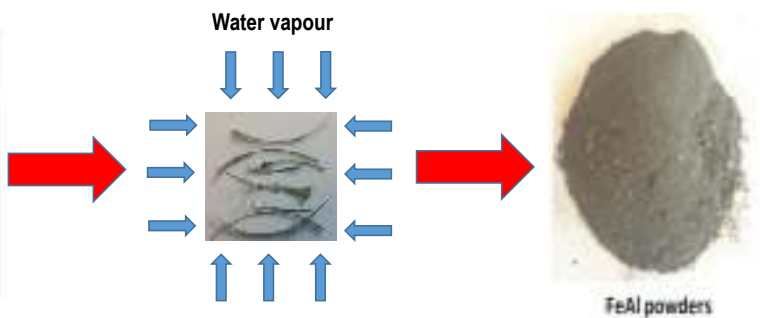

Fig. 2 Processes involved for the theoretical energy computation.

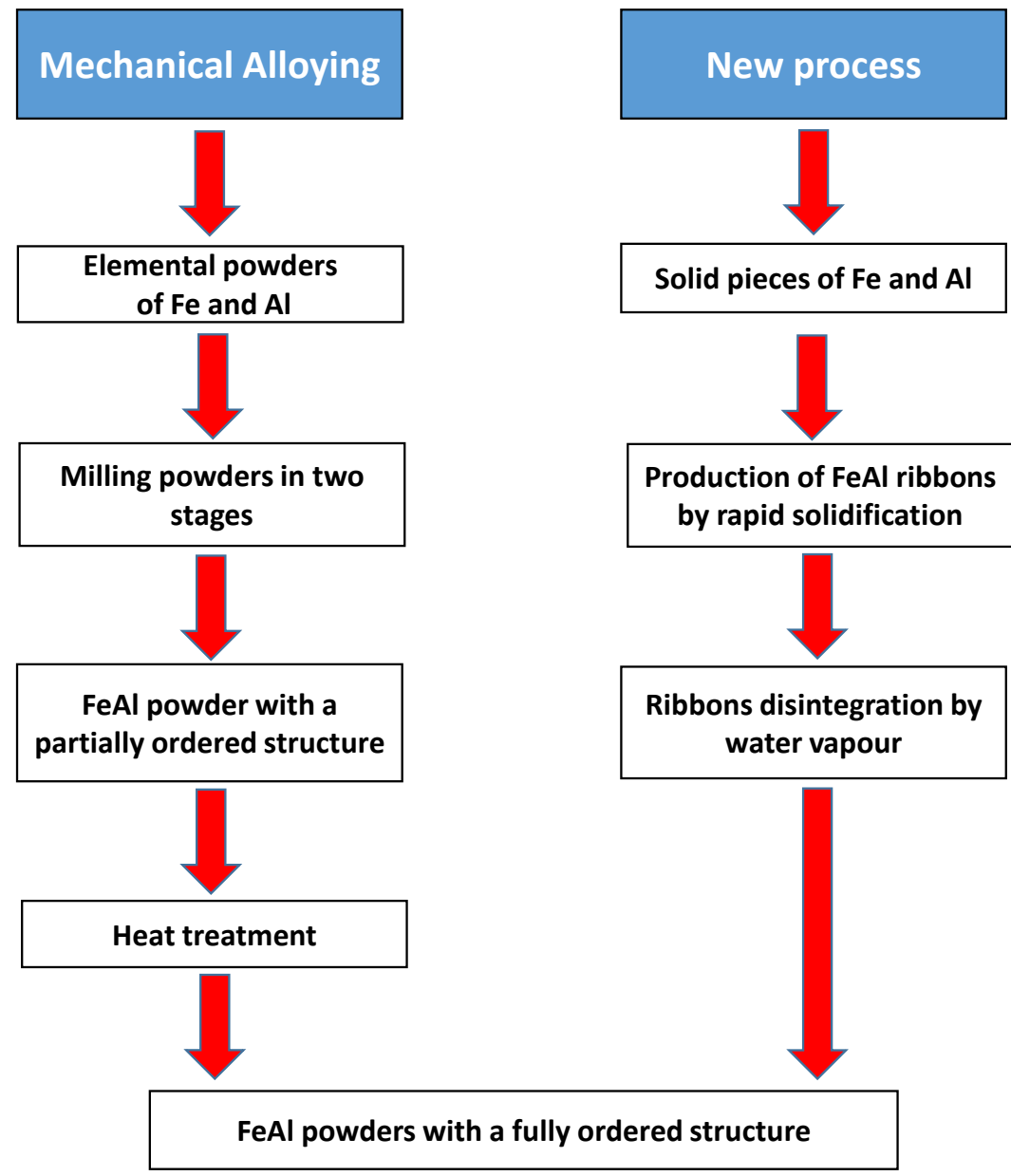




\section{Supplementary Files}

This is a list of supplementary files associated with this preprint. Click to download.

- Graphicalabstract.png 